01,13

\title{
Морфология и механические свойства микропроводов PrDyFeCoB
}

\author{
(C) О.В. Коплак ${ }^{1}$, Е.В. Дворецкая ${ }^{1}$, К.С. Кравчук ${ }^{2}$, А.С. Усейнов ${ }^{2}$, Д.В. Королев ${ }^{3}$, Р.А. Валеев ${ }^{3}$, \\ В.П. Пискорский ${ }^{3}$, О.С. Дмитриев ${ }^{4}$, Р.Б. Моргунов ${ }^{1,3,4}$ \\ ${ }^{1}$ Институт проблем химической фризики РАН, \\ Черноголовка, Россия \\ ${ }^{2}$ Технологический институт сверхтвердых и новых углеродных материалов, \\ Троицк, Россия \\ ${ }^{3}$ Всероссийский институт авиационных материалов, \\ Москва, Россия \\ ${ }^{4}$ Тамбовский государственный технический университет, \\ Тамбов, Россия \\ E-mail: o.koplak@gmail.com \\ Поступила в Редакцию 2 августа 2020 г. \\ В окончательной редакции 2 августа 2020 г. \\ Принята к публикации 12 августа 2020 г.
}

\begin{abstract}
Методом экстракции висящей капли расплава получены микропровода $\operatorname{PrDyFeCoB}$, диаметр и цилиндричность которых, регулируются скоростью вращения охлаждающего цилиндра и зависят от времени затвердевания капли на нем. Вариации режима охлаждения капли расплава приводят к изменению формы поперечного сечения от полностью цилиндрической до полукруга, полумесяца и почти плоской пластинки. Установлено, что режим охлаждения влияет не только на морфологию, но и на механические характеристики, различные для микропроводов разной формы, а также изменяет микротвердость и модуль Юнга разных поверхностей одного и того же микропровода.
\end{abstract}

Ключевые слова: редкоземельные и переходные металлы, микропровода, микротвердость, упругость, пластичность.

DOI: 10.21883/FTT.2020.12.50205.164

\section{1. Введение}

Микропровода и микроиглы открывают широкие возможности их практического применения в качестве магнитных пинцетов [1-3], магнито-импедансных датчиков поля [4-6] и многочисленных сенсоров деформации, механической нагрузки, температуры [7]. Микропровода на основе редкоземельных сплавов группы $R e-T M$-В $(R e-$ редкоземельные металлы, $T M$ - переходные металлы, В - бор), используемых для производства постоянных магнитов, в литературе встречаются сравнительно редко $[8,9]$, хотя аморфная фаза таких сплавов обладает близкой к нулю коэрцитивной силой. В наших недавних работах [10-15] был дан обстоятельный анализ фазового и химического состава, структуры и магнитных свойств микропроводов с ядром $\alpha$-Fe, покрытого оболочкой $\mathrm{PrDyFeCoB}$. Расслоение таких микропроводов на фазы и его преимущества для создания магнитных пинцетов описаны в [1]. Однако систематических исследований причин фазового расслоения и условий его получения не производилось. В частности, в ряде экспериментов, в которых мы в одних и тех же условиях получаем микропровода из расплава $\mathrm{PrDyFeCoB}$, обнаруживаются микропровода, как с ядром $\alpha$-Fe, так и без геометрически выделенного ядра, но с хаотическими включениями $\alpha$-Fe. Кроме того, получаются микропровода и без фазы $\alpha$-Fe, которые состоят из аморфной матрицы PrDyFeCoB c кристаллическими включениями ферромагнитных фаз $R e-T M$-В. Низкая воспроизводимость и необходимость селекции приготовленных микропроводов апостериори по-отдельности для каждого исследуемого микропровода редко отмечается авторами статей, хотя является реально существующей проблемой большинства исследований на эту тему.

В литературе преимущественно обсуждаются микропровода на основе переходных металлов $\mathrm{FeSi}, \mathrm{FeSiB}$, $\mathrm{FeCoSiB} \mathrm{[16-20],} \mathrm{а} \mathrm{также} \mathrm{немагнитные} \mathrm{микропровода}$ $\mathrm{Si}$ [21]. Даже в этих типах широко распространенных микропроводов, на исследование которых были направлены усилия сотен групп, отмечается низкая воспроизводилось свойств при одних и тех же макроскопических параметрах их изготовления. Это связано с дорогим и трудновыполнимым локальным контролем параметров расплава и его охлаждения и неявной подменой этих параметров средними значениями температуры расплава, скорости его поступления на охладитель и др. Значительную неопределенность вносят случайные градиенты температуры и концентрации элементов в расплаве. В многокомпонентных расплавах $R e-T M$-В положение усложняется неопределенностью, вносимой многообразием фаз, образующихся из расплава при разных температурах, конкуренцией динамики этих процессов, естественной непреодолимой стохастичностью самого процесса образования зародышей кристаллизующихся 
из расплава фаз, которая выступает на первый план в микрообъектах значительно сильнее, чем в объемных образцах. Поэтому аналитическое сравнение конечного результата изготовления микропроводов (магнитных, электрических, механических свойств, величины магнитоимпеданса и др.) нуждается в развитии, по меньшей мере, морфологического анализа их формы, которая, как показано в нашей работе, позволяет судить о режиме охлаждения расплава.

Цель настоящей работы заключалась в установлении закономерностей изменения формы поперечного сечения, морфологическом анализе микропроводов $\operatorname{PrDyFeCoB}$ и в анализе их механических свойств в зависимости от режима охлаждения капли расплава. В конечном итоге работа направлена на улучшение воспроизводимости свойств микропроводов путем морфологического анализа, позволяющего судить о локальной температуре и вязкости расплава в момент затвердевания микропровода.

\section{2. Методика и образцы}

В настоящей работе мы не имеем возможности для прямого измерения локальных микропараметров в момент затвердевания микропровода. Поэтому при сохранении макроскопического контроля параметров производства микропроводов о различиях в условиях затвердевания расплава судили по форме микропроводов. Микропровода были получены методом экстракции висящей капли расплава $\mathrm{PrDyFeCoB}$, разогретой электронным пучком. Экстракция происходила при касании разогретой капли поверхности водоохлаждаемого медного цилиндра, скорость вращения которого регулировали в пределах 20-55 m/s. Получившиеся микропровода (рис. 1) имели различную форму поперечного сечения (рис. 2), ширину $R$ в диапазоне $25-100 \mu \mathrm{m}$ и среднюю длину 10-20 mm. Эти параметры, а также площадь сечения (см. вставку на рис. 3) позволили впоследствии оценить объем капли $V$, превратившейся в микропровод.

Визуализация и определение геометрических характеристик и картирование элементного состава микропровода проводили методом сканирующей электронной микроскопии (СЭМ) и энергодисперсионной рентгеновской спектроскопии (EDX) на приборе Zeiss SUPRA c встроенной антивибрационной подвеской, шумоподавлением с семью режимами интеграции и усреднением, автоэмиссионным (термоэмиссионного типа) источником электронов, стабильностью лучше $0.2 \%$ в час, разрешением $1.7 \mathrm{~nm}$ при напряжении $15 \mathrm{kV}$ и $3.5 \mathrm{~nm}$ при $1 \mathrm{kV}$, увеличением до $\times 500000$.

Механические свойства микропровода были измерены с помощью инструментального вдавливания и царапания (скрайбирования) в нанотвердомере „NanoScan-4D“ [22], принцип действия которого основан на измерении и анализе зависимости нагрузки от глубины внедрения

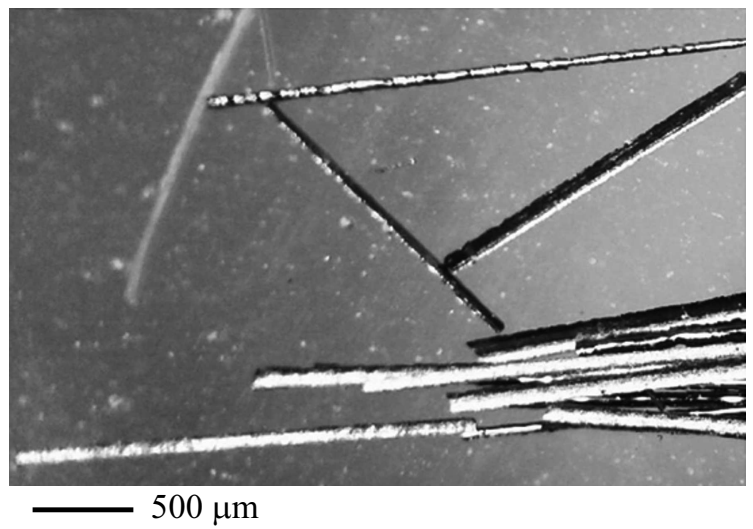

Pис. 1. Оптическое изображение микропроводов $\mathrm{PrDyFeCoB}$ в эпоксидной смоле.

алмазного индентора при вдавливании с постоянной скоростью в поверхность материала. Микропровода были помещены вертикально и/или горизонтально в полимерную матрицу на основе фенольных смол. Поверхность вертикальных образцов была обработана на шлифовально-полировочном оборудовании. С помощью оптического микроскопа были выбраны участки проведения индентирований. На торце микропровода проведены две серии уколов при максимальной нагрузке $5 \mathrm{mN}$, расстояние между отпечатками индентирования составило $10 \mu \mathrm{m}$, время нагружения при максимальной нагрузке $5 \mathrm{~s}$. Для калибровки прибора в качестве контрольного образца использовался плавленый кварц с твердостью $H=9.3 \mathrm{GPa}$ и модулем упругости $E=72.3 \mathrm{GPa}$.

\section{3. Экспериментальные результаты и обсуждение}

\section{1. Морфология микропроводов}

Микроиглы PrDy-FeCoB, получаемые методом экстракции висящей капли расплава (ЭВКР), отличаются диаметром, цилиндричностью (профилем поперечного сечения), гладкостью поверхности, однородностью по длине в зависимости от условий получения (рис. 2). Имеется определенная корреляция формы проводов со скоростью вращения охлаждающего цилиндра, при увеличении которой от 20 до $55 \mathrm{~m} / \mathrm{s}$, наблюдается более круглое сечение. Однако, и в пределах эксперимента с одной и той же скоростью вращения можно было наблюдать присутствие микропроводов с разной формой сечения, близкой к тем, что изображены на рис. $2, a-e$.

Для анализа формы микропровода была использована теория, развитая Таннером [23,24], которая обычно применяется к растеканию капли жидкости на плоской поверхности. В рамках этой теории ширина капли $R$ 

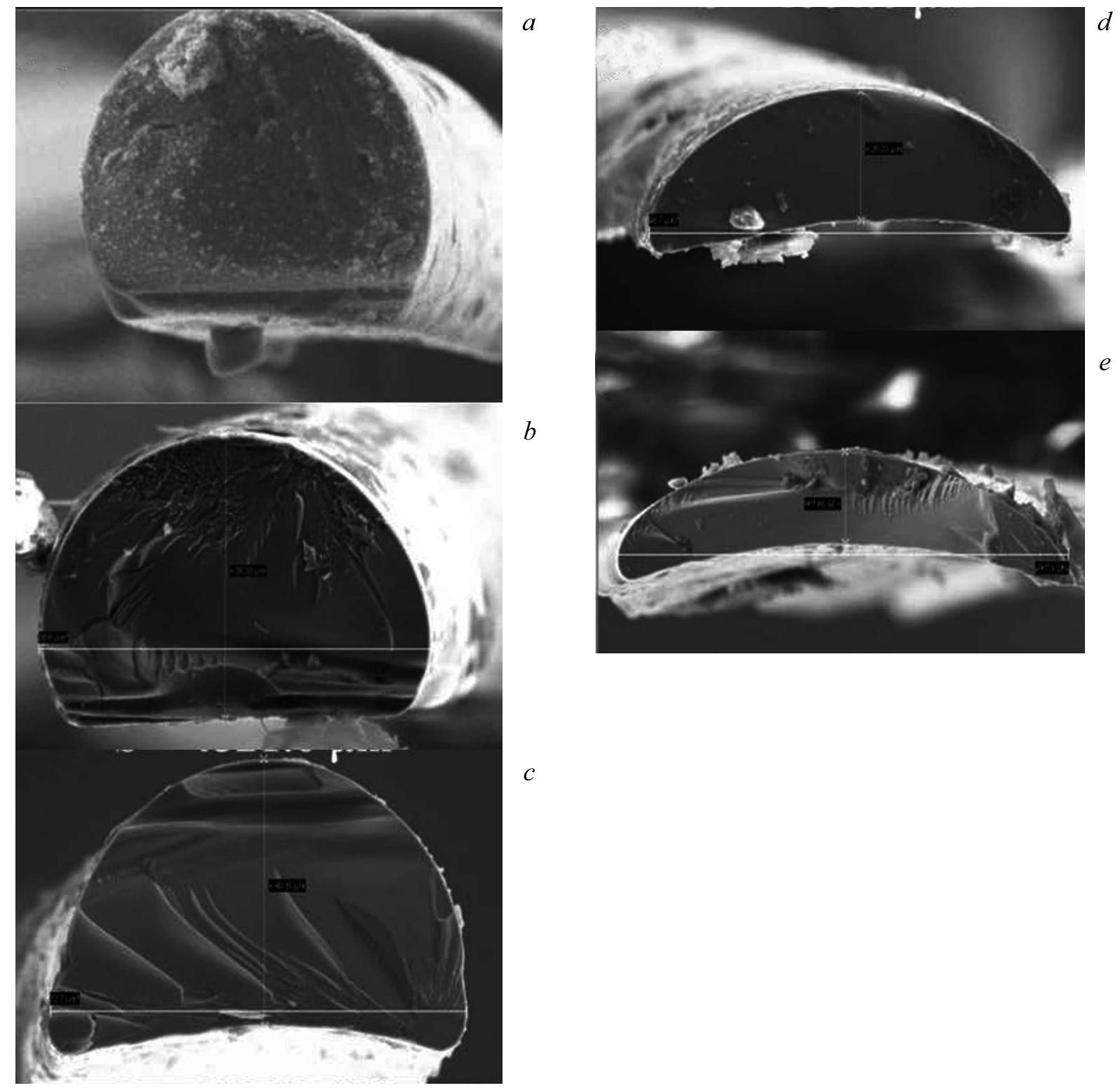

Рис. 2. Изображения поперечного сечения микропроводов различной формы в сканирующем электронном микроскопе. Скорость вращения охлаждающего цилиндра уменьшается от $(a)$ к $(e)$ в пределах $55-20 \mathrm{~mm} / \mathrm{s}$.

зависит от времени $t$ в соответствии с формулой [24]:

$$
\lg \left(\frac{R(t)}{V^{1 / 3}}\right)=\varepsilon \lg \left(\frac{\gamma t}{\eta}\right)
$$

где $V$ - объем капли, $\gamma$ - коэффициент поверхностного натяжениям жидкости, $\eta$ - вязкость жидкости. Величина $\varepsilon$ для сферической капли в теории Таннера равна строго $1 / 10$, однако в реальных экспериментах и при иных теоретических подходах она меняется в диапазоне 0.1-0.5 [23]. Управляющим фактором является вязкость $\eta$, поскольку именно она очень чувствительна к температуре, в отличие от коэффициента поверхностного натяжения $\gamma$. Конечно, строгое применение формулы (1) возможно только для круглой симметричной капли, однако, мы предположили, что динамика расширения капли расплава на поверхности в одном лишь направлении, поперечном микропроводу, будет сходной с динамикой расползания капли, а следовательно, и уравнение (1) пригодно для оценочных суждений о форме провода. Время застывания капли, очевидно, не превышает длительность поворота барабана на четверть периода, до момента, когда капля оторвется от барабана. Поэтому оценка времени охлаждения сверху дает $\sim 3 \cdot 10^{-3} \mathrm{~s}$ для радиуса барабана $0.1 \mathrm{~m}$ при скорости вращения $50 \mathrm{~m} / \mathrm{s}$. Отношение $\gamma / \eta$ для жидких металлов, которые находятся в сплаве (Fe, Co, Pr, Dy) близко к 2300 при температурах их плавления. Например, для $\mathrm{Fe}$ и $\mathrm{Co}$, значения $\eta$ равны $5.6 \mathrm{mPas}$ и $5.4 \mathrm{mPas}$, соответственно, а значения поверхностного натяжения этих металлов составляют $1.87 \mathrm{~N} / \mathrm{m}$ и $1.88 \mathrm{~N} / \mathrm{m}[25,26]$. 
Для редкоземельного $\operatorname{Pr}$ вязкость составляет $2.85 \mathrm{mPas}$ и поверхностное натяжение $0.71 \mathrm{~N} / \mathrm{m}$, т. е. обе величины примерно вдвое меньше, чем в переходных металлах. Хотя сами значения $\gamma$ и $\eta$ могут меняться в чистых металлах $\mathrm{Fe}, \mathrm{Co}, \mathrm{Pr}, \mathrm{Dy}$, их отношение $\gamma / \eta$ остается постоянным. Поэтому можно предполагать, что и для расплава в целом оно будет принимать значение, близкое к $\sim 300$. Следовательно, логарифм в правой части уравнения Таннера (1) равен $\sim 0.45$. Левая часть уравнения (1) может быть точно определена, например, для поперечного сечения микропровода $d$ (рис. 2, $d$ ). Площадь поперечного сечения микропровода составляет $S \sim 2000 \mu \mathrm{m}^{2}$, а объем исходной капли при типичной длине микропровода $10 \mathrm{~mm}$ составит $2 \cdot 10^{7} \mu \mathrm{m}^{3}$. Для ширины проволоки $R=120 \mu \mathrm{m}$ (рис. $2, d$ ) получим отношение $R / V^{1 / 3}=0.44$, которое приводит к значению левой части уравнения -0.35 , а параметр $\varepsilon$ в наших экспериментах составляет 0.77, что близко к значению 0.5 , полученному в [24]. Разумеется, изменение симметрии системы, неточное определения объема капли и другие факторы делают эту оценку очень приблизительной, однако она свидетельствует о применимости подхода Таннера и позволяет сделать вывод о том, что форма микропровода зависит от вязкости и поверхностного натяжения расплава в момент его застывания. Если уменьшать скорость вращения, то капля отрывается от круга за меньшее время и не успевает расползаться. Если подставить известные значения вязкости и поверхностного натяжения $[25,26]$ в формулу (1), получаются разумные значения времени затвердевания капли $\sim 1 \mathrm{~ms}$. Таким образом, форма микропровода удовлетворительно описывается известной формулой Таннера для растекания капли на плоскости [23].

Поскольку проведенный выше расчет оказался справедлив для точки, при которой левая часть уравнения (1) равна - 0.35, это дает основания считать, что и правая кинетическая часть этого уравнения равна этому же числу не только для этой точки, но и для других значений времени (рис. 3). Поэтому шкала на горизонтальной оси рис. 3 была по определению взята такой же, как и на вертикальной оси. Значения вертикальных координат точек были вычислены из геометрии поперечного сечения микропроводов, представленных на рис. 2. Из рис. 3 можно сделать вывод, что различие отношений $\gamma / \eta$ для микропроводов, представленных на рис. 2, составляет более порядка величины и обусловлено оно вариациями температуры в зоне контакта капли с охлаждающим цилиндром.

Поскольку фазовому расслоению материала в капле расплава способствует температурный градиент, обеспечивающий быстрейшую кристаллизацию легкоплавких фаз, было важно определить, насколько однородно распределены химические элементы в поперечном сечении микропровода. Для этого опыта был выбран микропровод $c$ (рис. 2). Типичный спектр $\mathrm{EDX}$ показан на рис. 4, $a$, результат мониторинга локального элементного EDX анализа поперечного сечения микропровода $d$ приведен

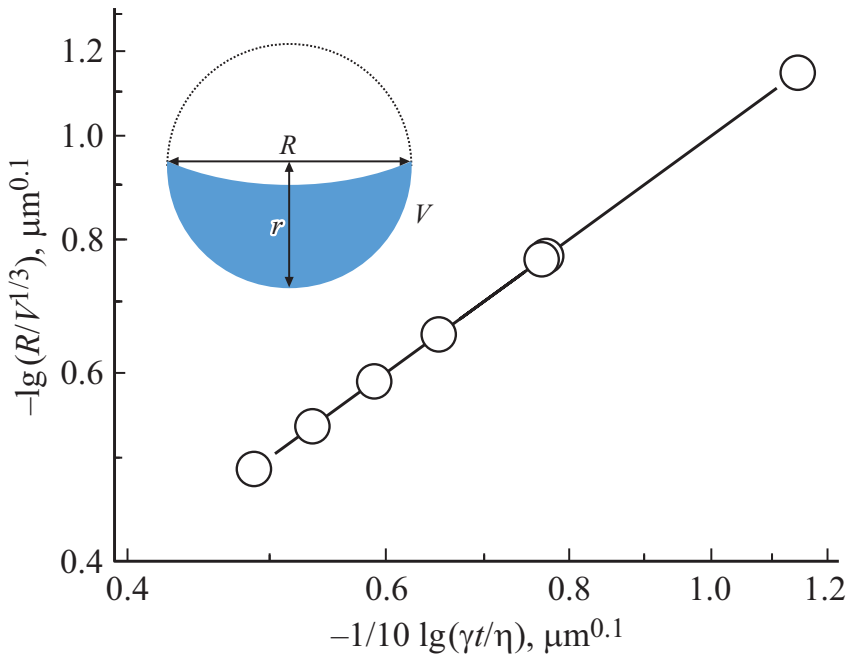

Рис. 3. Зависимость геометрической характеристики $R / V^{1 / 3}$ микропроводов $a-e$ из рис. 2 , от кинетической правой части уравнения Таннера, оцениваемой с помощью вязкости $\eta$ и поверхностного натяжения $\gamma$ расплава.

на рис. $4, b-e$. Спектр EDX содержит все химические элементы Dy, $\mathrm{Pr}, \mathrm{Co}, \mathrm{Fe}$, представленные в расплаве (рис. $4, b)$. Из распределения элементов можно сделать вывод, что имеет место относительно однородное распределение химических элементов Pr, Dy, Fe и Co по сечению микропровода без макроскопических выделений различных фаз. Можно отметить небольшие по размеру области, обедненные $\operatorname{Pr}$ и Со (рис. 4,c), которые могут соответствовать кристаллическим включениям фаз в аморфной матрице. Из полученных результатов можно сделать вывод, что при затвердевании расплава в нем не было температурного градиента, достаточно высокого для возникновения в микропроводе существенных макроскопических включений различных фаз железа (отсутствует ядро), а также фаз 2-14-1 и 1-4-1, известных в сплаве $R e-T M-\mathrm{B}$.

\section{2. Механические свойства микропроводов}

Механические свойства микропровода были измерены в двух ориентациях на торце микропровода в направлениях сканирования 1 и 2 (рис. 5,a) и вдоль оси микропровода $d$ на поверхности, пребывавшей в тепловом контакте с охлаждающим цилиндром в направлении 3 (рис. 5,b) с помощью инструментального вдавливания алмазного индентора Берковича в нанотвердомере NanoScan-4D. Значение микротвердости $H$ по Берковичу можно выразить как [27]:

$$
H=\frac{P_{\max }}{A_{c}},
$$

где $P_{\max }-$ максимальная нагрузка индентора, $A_{c}-$ квадрат проекции отпечатка, который определяется глубиной контакта $h_{c}$, т.е. расстоянием от поверхности до 

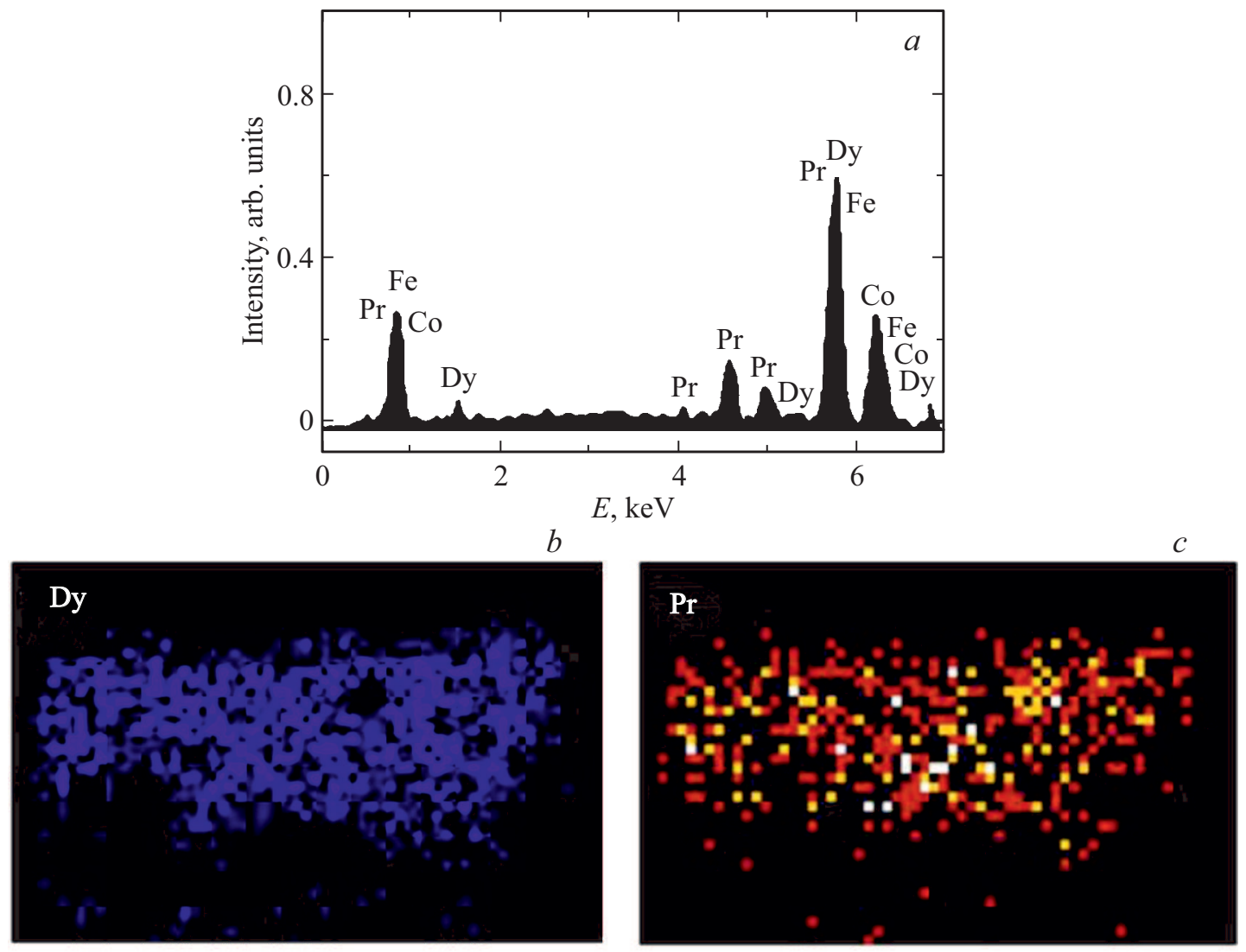

d

$e$
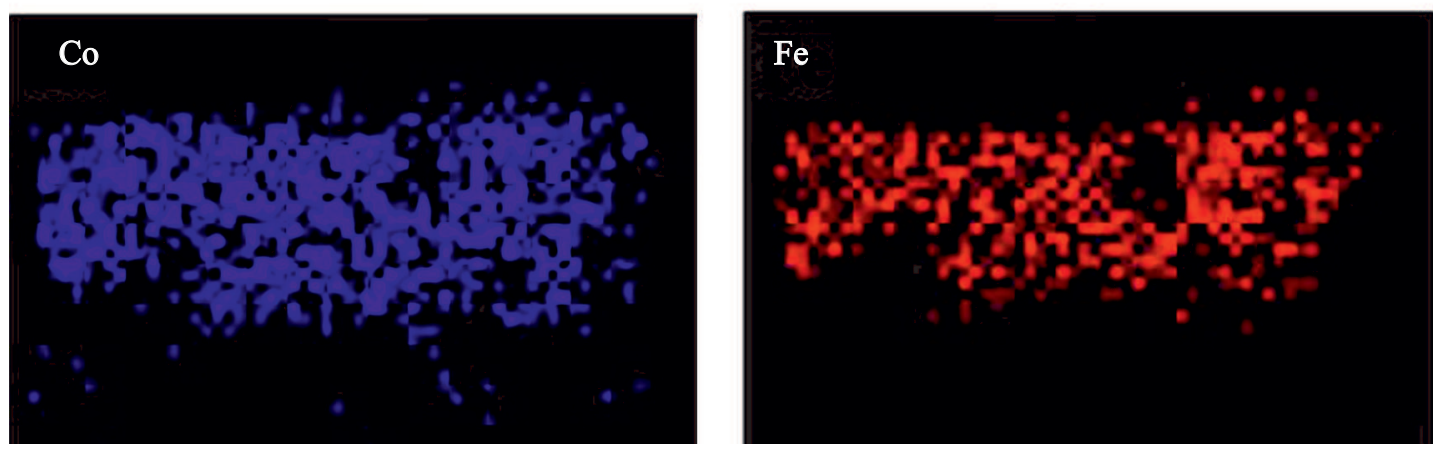

Рис. 4. $(a)$ - Спектр энергодисперсионного микроанализа поперечного сечения микропровода $d$, $(b-e)$ распределения химических элементов Dy, Fe, Co, Pr.

максимальной глубины проникновения. Для идеального индентора Берковича значение $A_{c}=24.5 h_{c}^{2}$. В данном случае значение приведенного модуля упругости

$$
E_{r}=\frac{1}{\beta} \cdot \frac{\sqrt{\pi}}{2} \cdot \frac{S_{k}}{\sqrt{A_{c}}},
$$

где $\beta=1.05-$ постоянная величина, определяющаяся формой индентора, $S_{k}$ - жесткость контакта, которая определяется по углу наклона касательной к кривой разгрузки $P(h)$ при максимальной нагрузке $P_{-} \max$ [27]:

$$
S_{k}=\left(\frac{d P}{d h}\right)_{P=P_{\max }} .
$$

Связь приведенного модуля $E_{r}$ и модуля Юнга $E$ испытываемого образца можно представить как [27]:

$$
\frac{1}{E_{r}}=\frac{1-v_{s}^{2}}{E}+\frac{1-v_{i}^{2}}{E_{i}}
$$

где $E_{i}$ - модуль Юнга материала индентора, $v_{s}, v_{i}-$ коэффициенты Пуассона анализируемого материала и индентора соответственно.

Установлено, что микротвердость продольного сечения микропровода $H=5.9 \pm 0.4 \mathrm{GPa}$ заметно меньше микротвердости поперечного сечения того же микропровода $H=9.3 \pm 0.8 \mathrm{GPa}$ (рис. 5,c-e). При этом модуль Юнга, напротив, имеет более высокое значение $E=207 \mathrm{GPa}$ для поперечного сечения, чем для 

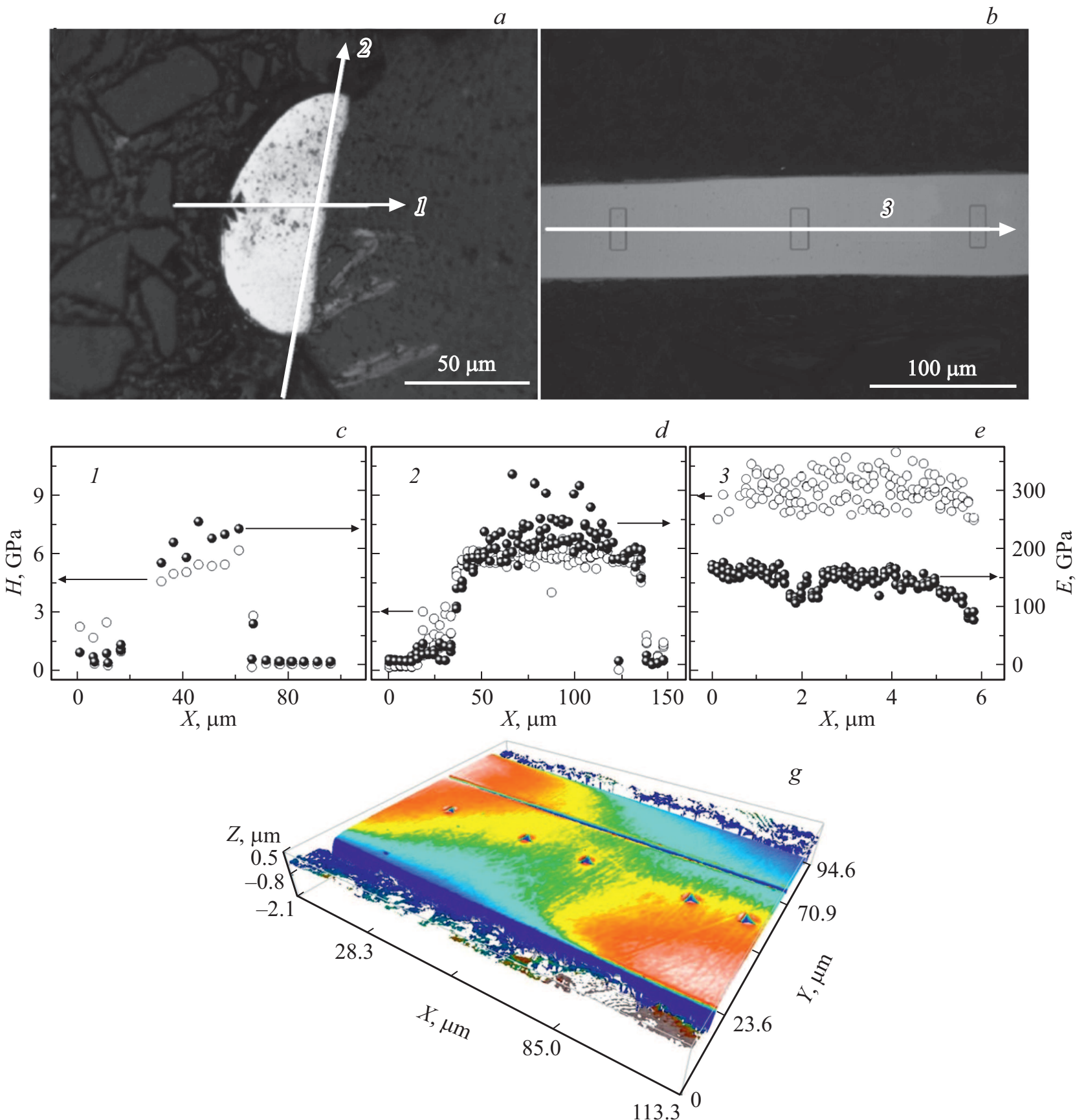

Рис. 5. Оптические изображения поперечного $(a)$ и продольного $(b)$ сечений микропровода $d$ с направлениями сканирования $1-3$ механических свойств (показаны стрелками). Профили микротвердости $H$ и модуля Юнга $E$ вдоль соответствующих направлений сканирования $1-3(c-e)$. Изображение поверхности микропровода, находившейся в тепловом контакте с охлаждающим цилиндром и подвергнутой после затвердевания микроиндентированию и скрайбированию для определения микротвердости и модуля Юнга $(g)$.

продольного сечения $E=140 \mathrm{GPa}$. Отпечатки индентирования и царапина, проведенная индентором, показаны на рис. $5, g$.

Различие механических свойств продольного и поперечного сечения одного и того же микропровода, очевидно связано с тем, что продольное сечение находилось в контакте с охлаждающим цилиндром и поэтому охлаждалось значительно быстрее. Можно предполагать поэтому, что доля аморфной фазы этого сечения выше, а доля поликристаллической фазы выше, чем для материала поперечного сечения микропровода.

Отношение твердости материала к модулю Юнга $H / E$ часто применяется для приблизительной оценки степени упрочнения и даже типа материалов. Типичные значения этой величины $H / E<0.04$ для крупнокристаллических металлов и сплавов; $H / E \approx 0.05-0.09$ для мелкокри- 


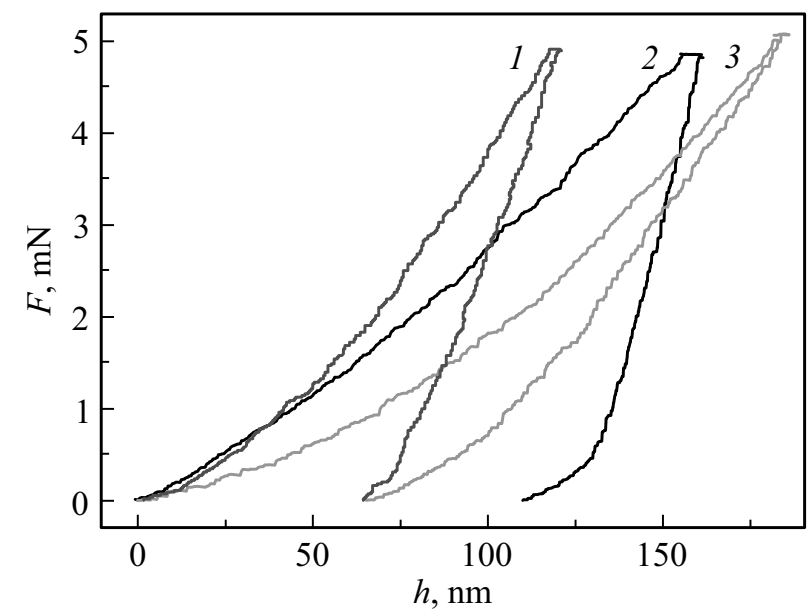

Рис. 6. Зависимости силы $F$ от глубины погружения индентоpa $h$ (кривые „нагружения-разгрузки“) в поперечных сечениях микропроводов $c(1)$ и $d(2)$, а также для контрольного образца плавленого кварца (3).

сталлических и наноматериалов, а также интенсивнодеформированных, мультифазных материалов, покрытий и пленок; $H / E \geq 0.1$ для аморфного или аморфнокристаллического состояния материала [28]. Это отношение в микропроводе с имело промежуточное значение 0.06 , характерное для мелкокристаллических или аморфно-кристаллических объектов. Были определены также микротвердости двух разных микропроводов $c$ и $d$ с различающимся поперечным сечением (рис. 2). Микротвердость поперечного сечения микропровода с составляла $13.4 \pm 0.4 \mathrm{GPa}$, что значительно выше, чем для микропровода $d$. При этом отношение $H / E$ составляло 0.03, указывая на преобладание кристаллической фазы. Этот факт подтверждает, что микропровод, охлаждаемый с большей скоростью, имеет большую долю аморфного состояния с увеличенным значением $H / E[28]$.

На рис. 6 представлены для сравнения зависимости силы $F$ от глубины погружения индентора $h$ в цикле „нагружение-разгрузка“ в поперечных сечениях микропроводов $c$ и $d$ (кривые 1 и 2, соответственно). Из рис. 6 следует значительное различие упругих и пластических свойств этих образцов. Кривая 3 на рис. 6 соответствует опыту на калибровочном образце кварца. В таблице

Механические характеристики микропроводов (d) и $(c)$ в поперечном и продольном сечениях

\begin{tabular}{l|c|c|c}
\hline \multicolumn{1}{c|}{ Характеристика } & $H, \mathrm{GPa}$ & $E, \mathrm{GPa}$ & $H / E$ \\
\hline $\begin{array}{l}\text { Поперечное сечение } 1 \\
\text { микропровода }(d)\end{array}$ & $5.85 \pm 0.35$ & $207 \pm 22$ & 0.03 \\
$\begin{array}{l}\text { Продольное сечение } 3 \\
\text { микропровода }(d)\end{array}$ & $9.3 \pm 0.8$ & $140 \pm 20$ & 0.06 \\
$\begin{array}{l}\text { Поперечное сечение } \\
\text { микропровода }(c)\end{array}$ & $13.4 \pm 1.7$ & $213 \pm 26$ & 0.06
\end{tabular}

для сравнения показаны модули Юнга и микротвердости всех поверхностей, описанных выше.

\section{4. Выводы}

1. Получены микропровода $\mathrm{PrDyFeCoB}$ различной формы поперечного сечения при разных скоростях вращения охлаждающего цилиндра. Увеличение скорости вращения ведет к сокращению времени затвердевания микропровода на барабане и улучшению теплоотвода за это время, обеспечивая меньшее растекание капли в соответствии с моделью Таннера. При высоких скоростях вращения $\sim 55 \mathrm{~m} / \mathrm{s}$ поперечное сечение микропроводов имеет почти цилиндрическую форму. При низких скоростях вращения $\sim 20 \mathrm{~m} / \mathrm{s}$ наблюдается линзообразная, почти плоская форма поперечного сечения микропровода.

2. Основной вклад в чувствительность формы поперечного сечения микропровода к скорости вращения охлаждающего цилиндра дает коэффициент вязкости расплава, зависящий от температуры сильнее, чем коэффициент поверхностного натяжения.

3. Микротвердость быстроохлажденного микропровода $H=13.4 \mathrm{GPa}$, форма поперечного сечения которого близка к цилиндрической, выше, чем микротвердость микропровода с линзообразной формой $H=9.3 \mathrm{GPa}$, полученного при низкой скорости затвердевания.

4. Установлено, что микротвердость поперечного сечения микропровода $H=5.9 \mathrm{GPa}$ меньше микротвердости быстрее охлаждаемого продольного сечения того же микропровода $H=9.3 \mathrm{GPa}$. При этом модуль Юнга поперечного сечения микропровода $E=207 \mathrm{GPa} \mathrm{мень-}$ ше, чем для продольного сечения того же микропровода $E=140 \mathrm{GPa}$.

\section{Благодарности}

Авторы благодарны Н.Н. Дремовой за получение СЭМ-изображений.

\section{Финансирование работы}

Работа выполнена при поддержке гранта РФФИ „Стабильность“ 20-32-70025, гранта 2644.2020.2 Президента Российской Федерации для государственной поддержки ведущих научных школ и программы ИПХФ РАН АААА-A19-119092390079-8.

\section{Конфликт интересов}

Авторы заявляют, что у них нет конфликта интересов.

\section{Список литературы}

[1] R. Morgunov, O. Koplak. Mater. Lett. 273, 127954 (2020).

[2] R. Sarkar, V.V. Rybenkov. Frontiers Phys. 4, 48(2016).

[3] P. Kollmannsberger, B. Fabry. The Rev. Sci. Instr. 78, 114301 (2007). 
[4] V. Zhukova, M. Ipatov, J. Gonzalez, J.M. Blanco, A. Zhukov. J. Appl. Phys. 103, 07E714 (2008).

[5] V. Zhukova, M. Ipatov, A. Zhukov. Sensors 9, 11, 9216 (2009).

[6] K. Mandal, S. Puerta, M. Vázquez, A. Hernando. Phys. Rev. B |bf62, 6598 (2000).

[7] H.-X. Peng, F. Qin, M.-H. Phan. Ferromagnetic microwire composites: from sensors to microwave applications. Ser. Eng. Mater. Proc. Springer, (2016). 245 p.

[8]R. Szary, I. Luciu, D. Duday, E.A. Perigo, T. Wirtz, P. Choquet, A. Michels. J. Appl. Phys. 117, 17D134 (2015).

[9] Z. Wusheng, L. Jinyun, S. Tianxiu, W. Zhengyun. J. Rare Earths 29, 1, 9410 (2011).

[10] R.B. Morgunov, O.V. Koplak, V.P. Piskorskii, D.V. Korolev, R.A. Valeev, A.D. Talantsev. J. Magn. Magn. Mater. 497, 166004 (2020).

[11] О.В. Коплак, В.Л. Сидоров, Е.И. Куницына, Р.А. Валеев, Д.В. Королев, В.П. Пискорский, Р.Б. Моргунов. ФТТ 61, 11, 2090 (2019).

[12] О.В. Коплак, Е.В. Дворецкая, А.Д. Таланцев, Д.В. Королев, Р.А. Валеев, В.П. Пискорский, А.С. Денисова, Р.Б. Моргунов. ФТТ 62, 4, 562 (2020).

[13] В.П. Пискорский, Р.А. Валеев, Д.В. Королев, Р.Б. Моргунов, И.И. Резчикова. Тр. ВИАМ 7, 79, 59 (2019).

[14] Р.Б. Моргунов, О.В. Коплак, А.Д. Таланцев, Д.В. Королев, В.П. Пискорский, Р.А. Валеев. Тр. ВИАМ 7, 79, 67 (2019).

[15] О.В. Коплак, Е.В. Дворецкая, Д.В. Королев, Р.А. Валеев, В.П. Пискорский, А.С. Денисова, Р.Б. Моргунов. ФТТ 62, 1187 (2020).

[16] A. Zhukova, V. Zhukov, J.M. Blancoc, A.F. Cobeno, M. Vazquez, J. Gonzalez. J. Magn. Magn. Mater. 258, 151 (2003).

[17] S.A. Baranov, D. Laroze, P. Vargas, M. Vazquez. Physica B: Condens. Matter 372, 324 (2006).

[18] Y. Takemura, H. Tokuda, K. Komatsu, S. Masuda, T. Yamada, K. Kakuno, K. Saito. IEEE Trans. Magn. 32, 4947 (1996).

[19] L. Galdun, T. Ryba, V.M. Prid, V. Zhukova, A. Zhukov, P. Diko, V. Kavecansky, Z. Vargova, R. Varga. JMMM 453, 96 (2018).

[20] M. Vazquez, K.L. Garcia, A. Zhukov, R. Varga, P. Vojtanik. J. Optoel. Adv. Mater. 6, 2, 581 (2004).

[21] A. Goryu, A. Ikedo, M. Ishida, T. Kawano. Nanotechnology 21, 12, 125302 (2010).

[22] I.I. Maslenikov, V.N. Reshetov, A.S. Useinov. Instrum. Exp. Tech. 58, 711 (2015).

[23] L.H. Tanner. J. Phys. D 12, 1473 (1979).

[24] A. Eddi, K.G. Winkels, J.H. Snoeijer. Phys Fluids 25, 013102 (2013).

[25] S. Rafai, D. Sarker, V. Bergeron, J. Meunier, D. Bonn. Langmuir 18, 10486 (2002).

[26] T. Iida, R. Guthrie, M. Isac, N. Tripathi. Met. And. Mater. Trans. B, 37b, 403 (2006).

[27] W.C. Oliver, G.M. Pharr. J. Mater. Res. 19, 3 (2004).

[28] A. Leyland, A. Matthews. Wear 246, 1 (2000).

Редактор Ю.Э. Китаев 